\title{
Do people from Taiwan have higher heavy metal levels than those from Western countries?
}

\author{
Ta-Yuan $\underline{\text { Liu }}^{1}$, MD, Yao-Min Hung ${ }^{2,3}$, MD, Wei-Chun $\underline{\text { Huang }}^{3,4}$, MD, PhD, Ming-Ling $\underline{\text { Wu}}^{5}$, MD, Shoa-Lin $\underline{\operatorname{Lin}}^{3,6}$, MD, FACC
}

\begin{abstract}
INTRODUCTION This study investigated whether heavy metal levels were higher in people from Taiwan as compared to those from Western countries.

METHODS We measured the level of heavy metals (lead, mercury, arsenic and cadmium) in the blood of 40 apparently healthy adults. Since mercury does not respond to ethylenediaminetetraacetic acid (EDTA) infusion, only urine lead, arsenic and cadmium levels were determined by applying the body burden concept after calcium disodium EDTA infusion. These three heavy metals were extracted from daily urine samples for three consecutive days.

RESULTS The mean blood lead, mercury and cadmium levels of the Taiwanese individuals $(24.46 \pm 9.69 \mu \mathrm{g} / \mathrm{L}, 9.64 \pm 6.98 \mu \mathrm{g} / \mathrm{L}$ and $0.73 \pm 0.27 \mu \mathrm{g} / \mathrm{L}$, respectively) were greater than those of the Americans. The Taiwanese also had greater blood mercury and cadmium levels than the Germans. The first-day urine lead, arsenic and cadmium levels were $77.9 \%, 33.1 \%$ and $62.4 \%$, respectively, of the total lead, arsenic and cadmium excretion during the three days. This indicates that the first-day urine lead and cadmium excretion represented most ( $>60 \%$ ) of the lead and cadmium excretion in those three days.

CONCLUSION This study demonstrated that the Taiwanese population has higher blood mercury and cadmium levels than Western populations. To study the urine lead and cadmium body burden of patients, detection of first-day, rather than three-day, urine lead and cadmium levels can be done, as the former yields results that are fairly representative, and is more time- and cost-effective.
\end{abstract}

Keywords: arsenic, cadmium, heavy metal, lead, mercury

\section{INTRODUCTION}

Several studies have suggested that blood lead and cadmium levels that are well below the current safety standards are associated with health risks, such as peripheral arterial disease, impaired renal function and elevated blood pressure. ${ }^{(1-3)}$ Menke et al reported that blood lead level was significantly associated with myocardial infarction and stroke mortality, even when it was below $0.48 \mu \mathrm{mol} / \mathrm{L}(10 \mu \mathrm{g} / \mathrm{dL}){ }^{(4)}$ A Taiwanese study by Huang reported that seafood contamination was very common in Taiwan, and that the lead and copper levels of the rivers in Taiwan were the highest in the world. ${ }^{(5)}$ The abstract of a study that investigated the concentration of heavy metals in the hair of 700 residents in Taiwan reported that most of the residents exhibited elevated heavy metal levels. ${ }^{(6)}$ However, this abstract is unpublished and only found on the Internet. ${ }^{(6)}$ To the best of our knowledge, there has been no formal report describing the heavy metal levels of healthy subjects in Taiwan. The two reports ${ }^{(5,6)}$ indicate that the finding of elevated heavy metal levels in Taiwanese people might not be unusual. Therefore, for the present study, we hypothesised that there may be greater levels of four common heavy metals (lead, mercury, arsenic and cadmium) in the blood of a Southern Taiwanese population than in Western populations.

The most reliable methods for measuring body lead burden are bone X-ray fluorescence studies and calcium disodium ethylenediaminetetraacetic acid $\left(\mathrm{CaNa}_{2}\right.$ EDTA) mobilisation tests.
This is because blood lead levels only reflect recent exposure to lead ${ }^{(7)}$ and not the lead burden of the body. According to recent reports, body lead burden can be measured by collecting 72-hour urinary lead excretion after intravenous infusion of $1 \mathrm{~g}$ of $\mathrm{CaNa}_{2} \mathrm{EDTA}^{(8,9)}$ These reports recommend the daily collection of urine for 72 hours in a high-volume container before the urine is sent for lead measurement. If most of the lead (or other heavy metal) can be excreted during the first 24 hours after $\mathrm{CaNa}_{2}$ EDTA infusion, then the level of heavy metal in the urine during the first 24 hours may be reflective of the body burden of these heavy metals. We hypothesised that the level of heavy metal in the urine collected in the first 24 hours would be positively correlated with the body burden of the heavy metal. Thus, the aim of the present study was twofold. First, we aimed to assess the levels of four common heavy metals (lead, mercury, arsenic and cadmium) in the blood of apparently healthy Taiwanese adults and to determine whether these heavy metal levels are greater than those of adults from Western countries. Second, we aimed to test our hypothesis that the level of heavy metal in first-day urine is reflective of the body burden of heavy metals (i.e. most heavy metals are excreted during the first 24 hours).

\section{METHODS}

A total of 40 apparently healthy persons (34 men, six women) were enrolled in the study, which was conducted from January

\footnotetext{
${ }^{1}$ Department of Internal Medicine, Tayuan Clinic, Taipei, ${ }^{2}$ Department of Emergency Medicine, Kaohsiung Veterans General Hospital, Kaohsiung, ${ }^{3}$ School of Medicine, National Yang Ming University, Taipei, ${ }^{4}$ Cardiovascular Center, Kaohsiung Veterans General Hospital, Kaohsiung, ${ }^{5}$ Division of Clinical Toxicology and Occupational Medicine, Department of Medicine, Taipei Veterans General Hospital, Taipei, ${ }^{6}$ Coronary Care Unit, Division of Cardiology, Department of Internal Medicine, Yuan's General Hospital, Kaohsiung, Taiwan, Republic of China

Correspondence: Dr Shoa-Lin Lin, Director, Coronary Care Unit, Division of Cardiology, Department of Internal Medicine, Yuan’s General Hospital, 162 Cheng-Kung First Road, Lingya District, Kaohsiung 80249, Taiwan, Republic of China. sllin@yuanhosp.com.tw
} 
2012 to December 2014. The mean age of the participants was $53.1 \pm 9.1$ (range 30-75) years. All 40 participants resided in Southern Taiwan and 36 of them lived in Kaohsiung city. The occupations of the participants were diverse and included doctors, nurses, technicians, businessmen, businesswomen, artists, military officers, teachers and housewives. None of the participants worked in the vicinity of factories that could have led to heavy metal exposure. The participants had normal liver function and normal renal function. They did not have a history of diabetes mellitus, coronary artery disease, stroke or any connective tissue disease. Although some of the participants had a history of hypertension, they had received appropriate antihypertensive treatment and their blood pressure (BP) was below 140/90 mmHg. This study was approved by the Institutional Review Board of Kaohsiung Veterans General Hospital, Taiwan. All of the 40 participants gave written informed consent before participating in this study.

The exclusion criteria were: (a) persistent elevated BP (i.e. $\mathrm{BP} \geq 140 / 90 \mathrm{mmHg}$ for more than two days); (b) creatinine $>1.3 \mathrm{mg} / \mathrm{dL}$ in men or $>1.2 \mathrm{mg} / \mathrm{dL}$ in women; (c) the presence of proteinuria; (d) baseline platelet level < 100,000/cumm; and (e) cigarette smoker within the previous two years.

The study participants were instructed to avoid eating fish, clams, lobsters and crabs two days before the $\mathrm{CaNa}_{2}$ EDTA injection. They were requested to drink at least $1,500 \mathrm{~mL}$ of water daily for three days to ensure a daily urine amount of more than $1,400 \mathrm{~mL}$. To assess the side effects of $\mathrm{CaNa}_{2}$ EDTA infusion, laboratory studies were done on the second day following $\mathrm{CaNa}_{2}$ EDTA injection, laboratory studies were done of the participants' creatinine level, fasting glucose level, haemoglobin A1c level, blood urea nitrogen level, alanine transaminase (ALT) level, aspartate transaminase (AST) level, blood cholesterol level, body burden of heavy metals and complete blood count. Other than that, the development of any symptom or discomfort after $\mathrm{CaNa}_{2}$ EDTA infusion was also recorded.

To determine the blood heavy metal levels of the participants, fasting venous blood specimens were drawn and placed into heparinised blood collection tubes (Becton Dickinson, NJ, USA) before $\mathrm{CaNa}_{2}$ EDTA infusion. If the heavy metal assays could not be completed within eight hours, the samples were refrigerated $\left(4^{\circ} \mathrm{C}-8^{\circ} \mathrm{C}\right)$. All of the samples were examined within ten days after preparation. To determine the lead, arsenic and cadmium levels in the blood, a mixed solution was prepared by combining $3 \mathrm{~mL}$ of $5 \%$ nitric acid, $9 \mathrm{~mL}$ of Triton 100, $2 \mathrm{~mL}$ of ethanol and deionised water to a volume of $100 \mathrm{~mL}$. For each participant, $0.4 \mathrm{~mL}$ of blood sample was added to $0.4 \mathrm{~mL}$ of internal standard and $3.5 \mathrm{~mL}$ of mixed solution for analysis. To determine the blood mercury levels, $0.5 \mathrm{~mL}$ of blood sample was added to $0.5 \mathrm{~mL}$ of EDTA, $0.5 \mathrm{~mL}$ of cystine, $0.5 \mathrm{~mL}$ of internal standard and $2.5 \mathrm{~mL}$ of $30 \%$ hydrochloric acid. The blood samples were well mixed at room temperature prior to analysis and the mixtures for determining the level of heavy metals in the blood were centrifuged for five minutes at 5,000 rpm. The lead, mercury, arsenic and cadmium levels in the blood were determined using Elan 6100 DRC Plus inductively coupled plasma mass spectrometry (Perkin Elmer, Waltham, USA). All the calibrators and blood samples were placed in the auto-sampler tray.

Since mercury does not respond to $\mathrm{CaNa}_{2}$ EDTA infusion, only urine lead, arsenic and cadmium levels were determined by applying the body burden concept after $\mathrm{CaNa}_{2}$ EDTA infusion. To determine the lead body burden, we assessed the level of lead in the participant's urine using the modified EDTA mobilisation tests, as described in previous studies. ${ }^{(8-10)}$ The study participants were instructed to have their breakfasts before the $\mathrm{CaNa}_{2}$ EDTA infusion. Each participant received a slow intravenous infusion (over 2-3 hours) of $1 \mathrm{~g} \mathrm{CaNa}$ EDTA that was premixed with $250 \mathrm{~mL}$ of normal saline solution. The first five participants underwent $\mathrm{CaNa}_{2}$ EDTA infusion for three hours, and the next five participants underwent the $\mathrm{CaNa}_{2}$ EDTA infusion for 2.5 hours. Since none of these participants experienced any discomfort, the remaining 30 participants received the $\mathrm{CaNa}_{2}$ EDTA infusion slowly for two hours.

Following the infusion, all participants started collecting their urine samples. The 24-hour urine samples were collected for three consecutive days in three 2-L bottles to assess the body burden of lead. The urine samples were collected by spontaneous voiding. The total amount of urine collected per day was recorded for each participant. For heavy metal quantification, $10 \mathrm{~mL}$ of urine from the total daily urine was used. The total daily urine would be well mixed before the extraction of the $10 \mathrm{~mL}$ for heavy metal quantification. Urine lead levels were quantified using the coupled plasma-mass spectrometry. Urine cadmium and arsenic levels were determined using the same method. The amount of heavy metal (i.e. lead, arsenic and cadmium) in the urine was calculated using the following formula: heavy metal amount $(\mu \mathrm{g})=$ concentration of heavy metal in the urine $(\mu \mathrm{g} / \mathrm{L}) \times$ total daily urine volume (L).

Collected data was presented as mean \pm standard deviation. Shapiro-Wilk test, which was used to examine whether the collected data (i.e. the heavy metal levels in blood and urine) followed a normal distribution, revealed that the data followed a Gaussian distribution. The statistical significance of the intergroup differences was determined using one-way analysis of variance and the two-tailed $t$-test with Bonferroni correction. In order to assess the reproducibility of the measurements of the heavy metal levels, measurements of urine heavy metal levels were repeated for 20 of the 40 participants using another $10 \mathrm{~mL}$ of urine from the total daily urine (that had been well-mixed). Pearson correlation analysis was employed to assess whether the measurements were reproducible. A p-value $<0.05$ was considered statistically significant.

\section{RESULTS}

The levels of heavy metals in the blood and first-day urine of participants are shown in Table I. Mean blood lead, mercury, arsenic and cadmium levels were $24.46 \pm 9.69 \mu \mathrm{g} / \mathrm{L}$, $9.64 \pm 6.98 \mu \mathrm{g} / \mathrm{L}, 7.41 \pm 4.70 \mu \mathrm{g} / \mathrm{L}$ and $0.73 \pm 0.27 \mu \mathrm{g} / \mathrm{L}$, respectively. The mean first-day urine lead, arsenic and cadmium concentrations were $10.69 \pm 6.68 \mu \mathrm{g} / \mathrm{L}, 86.03 \pm 115.01 \mu \mathrm{g} / \mathrm{L}$ and $1.64 \pm 0.96 \mu \mathrm{g} / \mathrm{L}$, respectively. 
Table I. Level of heavy metals in the blood and urine of the participants $(n=40)$.

\begin{tabular}{|c|c|c|c|c|c|c|c|}
\hline \multirow[t]{3}{*}{ No. } & \multicolumn{7}{|c|}{ Heavy metal concentration ( $\mu \mathrm{g} / \mathrm{L}$ ) } \\
\hline & \multicolumn{4}{|c|}{ In blood } & \multicolumn{3}{|c|}{ In first-day urine } \\
\hline & $\mathbf{P b}$ & $\mathrm{Hg}$ & As & Cd & $\mathbf{P b}$ & As & Cd \\
\hline 1 & 15.65 & 21.76 & 16.24 & 0.93 & 6.89 & 97.80 & 1.63 \\
\hline 2 & 17.27 & 2.58 & 21.74 & 1.24 & 7.27 & 55.00 & 2.39 \\
\hline 3 & 16.50 & 4.02 & 10.04 & 0.93 & 5.29 & 58.63 & 1.17 \\
\hline 4 & 35.67 & 8.22 & 6.92 & 0.72 & 22.54 & 62.14 & 1.72 \\
\hline 5 & 10.10 & 28.65 & 13.70 & 0.61 & 3.25 & 146.79 & 0.73 \\
\hline 6 & 17.39 & 6.06 & 3.84 & 0.63 & 6.97 & 24.85 & 1.32 \\
\hline 7 & 19.87 & 5.30 & 4.22 & 0.59 & 11.87 & 62.31 & 2.14 \\
\hline 8 & 30.93 & 14.16 & 5.39 & 1.05 & 10.21 & 30.45 & 1.70 \\
\hline 9 & 22.15 & 10.47 & 5.30 & 1.06 & 18.28 & 31.26 & 4.07 \\
\hline 10 & 26.83 & 10.84 & 3.99 & 0.99 & 17.76 & 49.60 & 1.90 \\
\hline 11 & 26.86 & 5.24 & 9.46 & 0.38 & 7.89 & 70.56 & 0.77 \\
\hline 12 & 18.11 & 8.04 & 2.96 & 0.91 & 10.91 & 25.77 & 2.70 \\
\hline 13 & 16.58 & 27.29 & 6.17 & 0.55 & 12.23 & 736.48 & 1.57 \\
\hline 14 & 24.60 & 6.47 & 6.30 & 1.17 & 5.20 & 37.99 & 1.95 \\
\hline 15 & 30.88 & 8.87 & 9.83 & 0.89 & 6.91 & 48.00 & 1.57 \\
\hline 16 & 31.08 & 16.14 & 7.78 & 0.96 & 16.10 & 156.79 & 4.19 \\
\hline 17 & 14.68 & 4.56 & 7.64 & 0.71 & 8.08 & 62.61 & 1.61 \\
\hline 18 & 26.79 & 9.01 & 8.20 & 0.60 & 28.78 & 52.31 & 2.39 \\
\hline 19 & 55.20 & 2.15 & 2.37 & 0.93 & 9.85 & 65.14 & 1.03 \\
\hline 20 & 34.06 & 11.69 & 7.80 & 0.56 & 2.15 & 123.12 & 0.85 \\
\hline 21 & 39.33 & 1.20 & 2.79 & 0.55 & 11.48 & 37.57 & 1.03 \\
\hline 22 & 32.87 & 6.19 & 3.85 & 0.79 & 6.71 & 16.24 & 0.69 \\
\hline 23 & 25.73 & 4.05 & 3.94 & 0.69 & 0.94 & 30.54 & 0.39 \\
\hline 24 & 20.17 & 5.07 & 4.32 & 0.64 & 8.91 & 25.09 & 1.35 \\
\hline 25 & 5.83 & 5.89 & 2.95 & 0.23 & 7.68 & 85.59 & 0.86 \\
\hline 26 & 34.99 & 5.84 & 10.60 & 0.93 & 21.78 & 162.10 & 3.58 \\
\hline 27 & 9.44 & 6.53 & 6.72 & 0.42 & 5.04 & 25.61 & 0.52 \\
\hline 28 & 15.06 & 2.66 & 3.62 & 0.57 & 7.44 & 22.28 & 1.27 \\
\hline 29 & 24.19 & 1.19 & 3.71 & 0.36 & 3.86 & 13.86 & 0.33 \\
\hline 30 & 12.66 & 7.64 & 8.18 & 0.66 & 4.89 & 80.00 & 1.22 \\
\hline 31 & 17.22 & 15.93 & 6.39 & 0.58 & 7.40 & 88.26 & 1.59 \\
\hline 32 & 20.70 & 20.11 & 12.50 & 0.97 & 8.37 & 126.81 & 1.20 \\
\hline 33 & 27.93 & 11.82 & 6.16 & 0.33 & 13.77 & 85.97 & 0.93 \\
\hline 34 & 18.51 & 6.96 & 7.99 & 0.64 & 5.86 & 11.86 & 1.04 \\
\hline 35 & 23.61 & 19.04 & 5.73 & 0.60 & 16.56 & 137.30 & 2.26 \\
\hline 36 & 30.56 & 16.46 & 7.31 & 0.90 & 29.35 & 87.20 & 3.24 \\
\hline 37 & 25.99 & 20.99 & 23.73 & 1.37 & 8.68 & 196.23 & 1.22 \\
\hline 38 & 37.61 & 4.77 & 3.88 & 0.44 & 8.39 & 35.57 & 0.91 \\
\hline 39 & 30.98 & 7.89 & 5.83 & 0.34 & 18.00 & 115.74 & 1.44 \\
\hline 40 & 33.72 & 3.89 & 6.41 & 0.92 & 14.08 & 59.79 & 3.32 \\
\hline
\end{tabular}

As: arsenic; Cd: cadmium; $\mathrm{Hg}$ : mercury; $\mathrm{Pb}$ : lead

Fig. 1 shows the levels of heavy metals in the urine of the participants over the three days. The mean level of lead in the urine on the first day (i.e. $18.44 \pm 9.26 \mu$ g) was significantly greater than that on the second day (i.e. $3.03 \pm 2.28 \mu \mathrm{g}$ ) and third day (i.e. $2.02 \pm 1.34 \mu \mathrm{g})(\mathrm{p}<0.001$ for all comparisons). Similarly, the mean level of cadmium on the first day (i.e. $2.77 \pm 1.41 \mu \mathrm{g}$ ) was significantly greater than that on the second day (i.e. $1.03 \pm 0.93 \mu \mathrm{g}$ ) and third day (i.e. $0.85 \pm 0.68 \mu \mathrm{g})(\mathrm{p}<0.001$ for all comparisons).
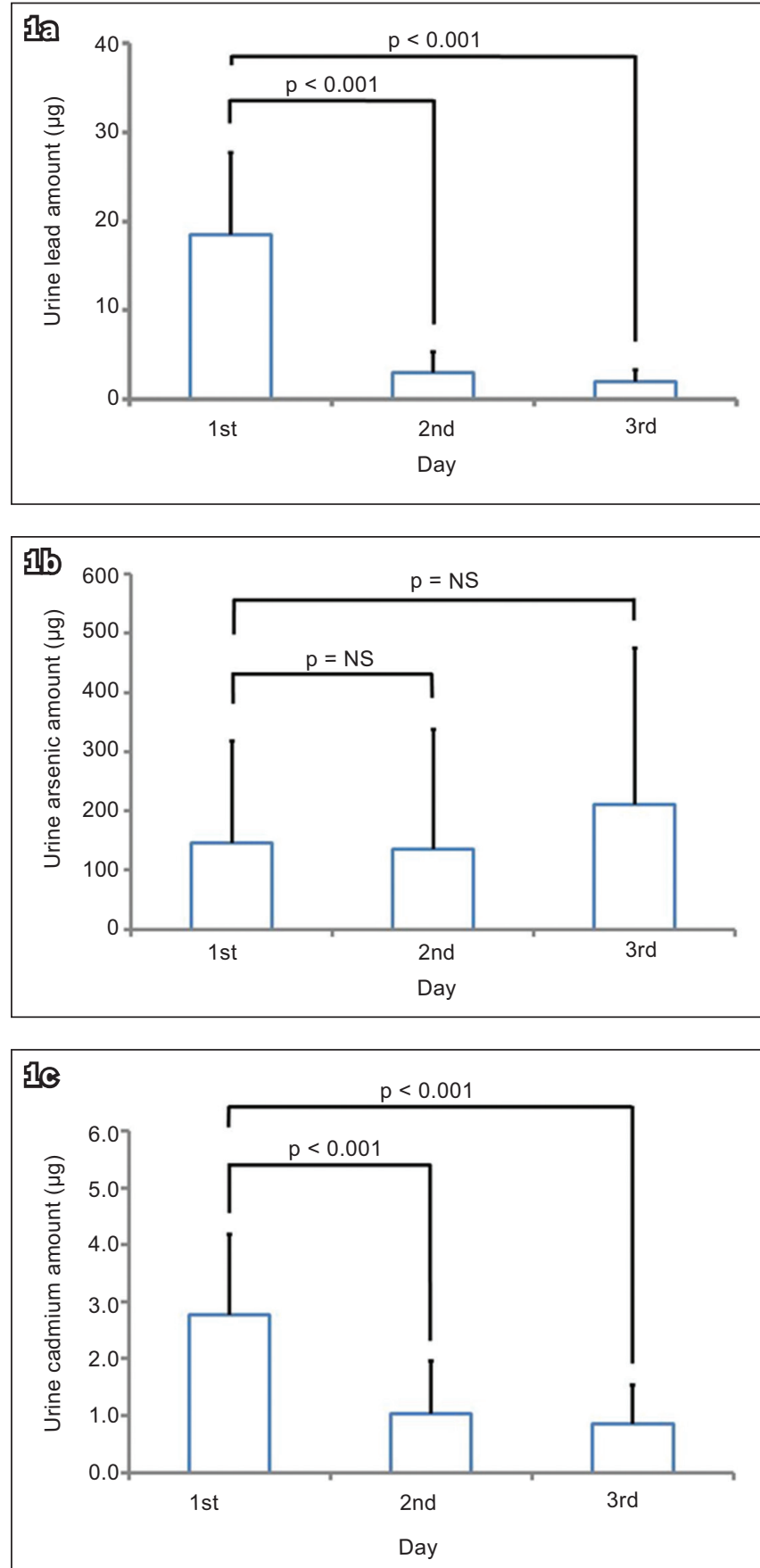

Fig. 1 Bar graphs show the levels of (a) lead, (b) arsenic and (c) cadmium in the urine of 40 participants over three days. NS: not significant

Percentage analysis showed that the amounts of lead and cadmium in the urine on the first day were $77.9 \%$ and $62.4 \%$, respectively, of the total lead and cadmium excretion during the three days (Fig. 2). This finding suggests that it is unnecessary to collect urine lead and cadmium data for three days in persons with normal creatinine levels (i.e. creatinine $<1.3 \mathrm{mg} / \mathrm{dL}$ in men and $<1.2 \mathrm{mg} / \mathrm{dL}$ in women). However, the level of arsenic in the urine on the first day was only $33.1 \%$ of the total arsenic excretion during the three days. The level of arsenic in the urine on the first day was also not significantly greater than that on the second day and third day. This suggests that first-day urine arsenic levels cannot be used to reflect the body burden of arsenic. 


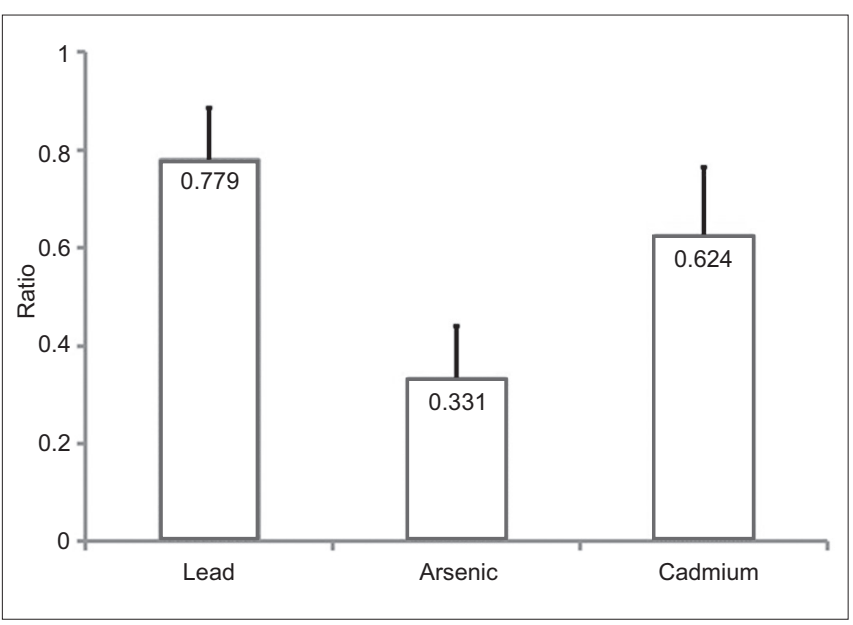

Fig. 2 Bar graph shows the ratio of the amount of heavy metal in urine on the first day to the total amount of heavy metal in urine for three days, for three heavy metals, lead, arsenic and cadmium.

The reproducibility of the measurements of the heavy metals in urine (analysed in 20 participants) was good. The results of Pearson correlation analysis are shown in Table II; all of the r-values were $\geq 0.916$ and all of the $p$-values were $<0.001$.

Table III compares the heavy metal levels (in blood) of three different populations. The mean levels of lead, mercury and cadmium in the blood of our study population $(24.46 \mu \mathrm{g} / \mathrm{L}$, $9.64 \mu \mathrm{g} / \mathrm{L}$ and $0.73 \mu \mathrm{g} / \mathrm{L}$, respectively) were greater than those of persons from the United States. ${ }^{(11)}$ The mean blood mercury and cadmium levels of our study population were also greater than those of a German population. ${ }^{(12)}$ However, the mean blood lead level of our population was lower than that of the aforementioned German population (i.e. $31.00 \mu \mathrm{g} / \mathrm{L}$ ). ${ }^{(12)}$

As a meticulous and slow infusion rate was used during $\mathrm{CaNa}_{2}$ EDTA solution infusion and fasting was not required, all 40 participants underwent $\mathrm{CaNa}_{2}$ EDTA solution infusion without experiencing any discomfort. There was no substantial change in the participants' biochemical levels and complete blood counts before and after $\mathrm{CaNa}_{2}$ EDTA infusion.

\section{DISCUSSION}

The present study investigated the blood heavy metal levels of apparently healthy adults from Southern Taiwan. It also examined the level of heavy metals in the urine (i.e. body burden of the heavy metals) of the same population after $\mathrm{CaNa}_{2}$ EDTA infusion. Several studies have used the body burdens of lead to determine the relationship between environmental exposure to lead and progressive chronic kidney diseases..$^{(8,9,13,14)}$ These studies used the total lead excretion for three days to assess the lead burden after $\mathrm{CaNa}_{2}$ EDTA infusions. The present study demonstrated that first-day lead and cadmium urine excretion could adequately reflect the body burdens of lead and cadmium. As shown in Fig. 2, the lead and cadmium excretion on the first day were $77.9 \%$ and $62.4 \%$, respectively, of the total amount of excreted lead and cadmium during the three days. Since the amounts of lead and cadmium excreted on the first day were more than $60 \%$ of the total lead and cadmium excreted in the three days, firstday urine can be used to represent the body burden of lead and
Table II. Results of the Pearson correlation analysis testing the reproducibility of the heavy metal levels in the urine of 20 participants.

\begin{tabular}{|c|c|c|c|c|c|c|}
\hline \multirow[t]{2}{*}{ Variable } & \multicolumn{2}{|c|}{ Day 1} & \multicolumn{2}{|c|}{ Day 2} & \multicolumn{2}{|c|}{ Day 3} \\
\hline & $\mathbf{r}$ & p-value & $\mathbf{r}$ & p-value & $\mathbf{r}$ & p-value \\
\hline Lead & 0.998 & $<0.001$ & 0.947 & $<0.001$ & 0.990 & $<0.001$ \\
\hline Arsenic & 0.999 & $<0.001$ & 0.998 & $<0.001$ & 0.999 & $<0.001$ \\
\hline Cadmium & 0.998 & $<0.001$ & 0.916 & $<0.001$ & 0.986 & $<0.001$ \\
\hline
\end{tabular}

r: correlation coefficient

Table III. Comparison of blood heavy metal levels in three populations.

\begin{tabular}{lcccc}
\hline Population & \multicolumn{4}{c}{ Blood level $(\boldsymbol{\mu g} / \mathrm{L})$} \\
\cline { 2 - 5 } & $\mathbf{P b}$ & Hg & As & Cd \\
\hline American(11) $^{(14.50}$ & 0.32 & NA & 0.41 \\
German $^{(12)}$ & 31.00 & 0.58 & NA & 0.44 \\
Taiwanese (current study) & 24.46 & 9.64 & 7.41 & 0.73 \\
\hline
\end{tabular}

As: arsenic; Cd: cadmium; Hg: mercury; NA: not available; Pb: lead

cadmium, instead of total urine collected for three consecutive days. The use of first-day urine to estimate the body burdens of lead and cadmium is relatively simpler and saves time and money. A similar concept, in which 24-hour urine instead of three-day urine was used to assess lead and mercury poisoning, has been reported recently. ${ }^{(15)}$ We opine that the use of first-day urine for clinically evaluating the body burdens of lead and cadmium via CaNa, EDTA infusion is a practical method.

A previous study reported that disodium EDTA was not safe, resulting in its subsequent removal from the market in June 2008. ${ }^{(16)}$ On the other hand, $\mathrm{CaNa}_{2}$ EDTA infusion has been approved for use in the treatment of heavy metal toxicity by the United States' Food and Drug Administration. The present study used $\mathrm{CaNa}_{2}$ EDTA infusion, which differs from the previously used disodium EDTA. Since mercury usually binds to either sodium 2,3-dimercaptopropane-1-sulfonate (DMPS) or meso 2,3-dimercaptosuccinic acid (DMSA), ${ }^{(17)}$ we did not evaluate the body burden of mercury using $\mathrm{CaNa}_{2}$ EDTA infusion. To assess the body burden of mercury, the chelation agent must be changed to either DMPS or DMSA. As heavy metals react differently to different reagents, it is important to choose appropriate tests (and reagents) for detecting the presence of heavy metals, depending on the suspected source of heavy metal exposure.

The present study revealed that the amount of arsenic in urine fluctuated considerably on different days. This phenomenon may be due to two reasons: (a) discontinuing the consumption of prohibited food types for only two days may have been insufficient; and (b) although the participants were instructed to avoid eating fish, clams, lobsters and crabs two days before the $\mathrm{CaNa}_{2}$ EDTA injection, they consumed other foods that may have contained organic arsenic (which is not harmful to the body). The test used in the present study, as well as most available tests, detects both organic and inorganic arsenic. We speculate that this is probably the reason that no blood arsenic data was reported in the National Health and Nutrition Examination Survey III ${ }^{(11)}$ and the German Environmental Survey III study ${ }^{(12)}$ (Table III). 
In the present study, the occupations of the 40 participants included doctors, nurses, technicians, businessmen, businesswomen, artists, military officers, teachers and housewives; none of the participants worked in the vicinity of factories, which may have led to heavy metal exposure. The working environments of the participants were better than those of persons from occupations associated with heavy metal exposure (e.g. chemical factory worker, painter, car repairman, airplane maintenance personnel, long-term gas station worker, construction worker, battery manufacturer and recycler, firing range instructor and plastic manufacturer). If we had included persons from the latter group in the study, the heavy metal levels obtained may have been higher. We speculate that the heavy metal levels of Taiwanese persons are substantially high, and this should be of concern to the public and medical community.

A previous study reported that prolonged exposure to lead may cause cardiovascular, renal and hepatic dysfunction. ${ }^{(18)}$ Three epidemiological studies have demonstrated a positive association between blood lead levels and rate of renal function impairment. ${ }^{(19-21)}$ Lin et al conducted EDTA mobilisation tests to assess the body burden of lead in patients with different degrees of renal insufficiency and no known lead exposure; their results suggest that long-term, low-level environmental lead exposure may be associated with the progression of renal insufficiency. ${ }^{(8,9)}$ They also showed that long-term, low-level environmental lead exposure may be associated with renal tubular and glomerular damage in patients with immunoglobulin A nephropathy ${ }^{(22)}$ and in residents who had been living near a lead battery factory for more than ten years. ${ }^{(23)}$ The findings of these studies suggest that there may be a positive association between long-term lead exposure (resulting in a high body burden of lead) and impaired kidney function.

Regular monitoring of renal function over an extended period of time is needed to determine whether persons who are exposed to high levels of lead are more likely to develop renal issues as compared to persons who are exposed to lower levels of lead. A nationwide survey on heavy metal exposure should be conducted in Taiwan in order to investigate this important health issue; this survey should involve a large number of study participants, and be done using a standardised questionnaire and blood or urine heavy metal tests.

The present study was not without limitations. It involved a relatively small study population $(n=40)$. Also, all of the participants resided in Southern Taiwan. Hence, the results may not be representative of the general population of Taiwan.

Previous studies used the conventional method of collecting total urine for three consecutive days to reflect the body burden of lead in end-stage renal disease. ${ }^{(8,9,13,14)}$ However, the findings of the present study demonstrated that first-day urine may be sufficient for determining the body burden of lead and cadmium in healthy persons. As all of the 40 participants had normal creatinine levels, it is uncertain whether this concept is applicable to patients with slightly elevated creatinine levels. Future studies are needed to determine whether this concept is applicable to patients with mildly abnormal renal function.
In conclusion, to the best of our knowledge, our study is the first to investigate the levels of four common heavy metals in the blood of healthy Taiwanese adults. It showed that Taiwanese people have higher blood mercury and cadmium levels than people from Western countries. The lead and cadmium excretion on the first day represented most of the lead and cadmium excreted in the three days after $\mathrm{CaNa}_{2}$ EDTA infusion. Thus, the collection of only first-day urine, instead of total urine for three days, is a practical method for clinically evaluating lead and cadmium body burdens.

\section{ACKNOWLEDGEMENTS}

This study was supported by the Veterans General Hospital, Taiwan, and the University System of Taiwan Joint Research Programme (Grant No. VGHUST100-G3-2-1).

\section{REFERENCES}

1. Navas-Acien A, Selvin E, Sharrett AR, et al. Lead, cadmium, smoking, and increased risk of peripheral arterial disease. Circulation 2004; 109:3196-201.

2. Telisman S, Jurasović J, Pizent A, Cvitković P. Blood pressure in relation to biomarkers of lead, cadmium, copper, zinc, and selenium in men without occupational exposure to metals. Environ Res 2001; 87:57-68.

3. Vupputuri $\mathrm{S}, \mathrm{He}$ J, Muntner $\mathrm{P}$, et al. Blood lead level is associated with elevated blood pressure in blacks. Hypertension 2003; 41:463-8.

4. Menke A, Muntner P, Batuman V, Silbergeld EK, Guallar E. Blood lead below $0.48 \mathrm{micromol} / \mathrm{L}(10 \mathrm{microg} / \mathrm{dL})$ and mortality among US adults. Circulation 2006; 114:1388-94.

5. Huang HR. [The contamination of sea food in Taiwan was the highest of the world]. Common Health Magazine 2002; 39:154-63. Chinese.

6. Liu TZ. Heavy metal hazard is a very heavy burden for Taiwanese people [online]. Available at: http://www.shop2000.com.tw/MT/news/19206. Accessed October 5, 2014.

7. Pollock CA, Ibels LS. Lead nephropathy--a preventable cause of renal failure. Int J Artif Organs 1988; 11:75-8.

8. Lin JL, Ho HH, Yu CC. Chelation therapy for patients with elevated body lead burden and progressive renal insufficiency. A randomized, controlled trial. Ann Intern Med 1999; 130:7-13.

9. Lin JL, Tan DT, Hsu KH, Yu CC. Environmental lead exposure and progressive renal insufficiency. Arch Intern Med 2001; 161:264-71.

10. Batuman V, Maesaka JK, Haddad B, et al. The role of lead in gouty nephropathy. N Engl J Med 1981; 304:520-3.

11. Centers for Disease Control and Prevention. National Report on Human Exposure to Environmental Chemicals. Third edition, 2005. Available at: http://www.cdc. gov/exposurereport/. Accessed September 5, 2014.

12. Becker K, Kaus S, Krause C, et al. German Environmental Survey 1998 (GerES III): environmental pollutants in blood of the German population. Int J Hyg Environ Health 2002; 205:297-308.

13. Lin JL, Lin-Tan DT, Hsu KH, Yu CC. Environmental lead exposure and progression of chronic renal diseases in patients without diabetes. N Engl J Med 2003; 348:277-86

14. Lin JL, Lin-Tan DT, Li YJ, Chen KH, Huang YL. Low-level environmental exposure to lead and progressive chronic kidney diseases. Am J Med 2006; 119:707.e1-9.

15. Brodkin E, Copes R, Mattman A, et al. Lead and mercury exposures: interpretation and action. CMAJ 2007; 176:59-63.

16. Mitka M. Chelation therapy trial halted. JAMA 2008; 300:2236.

17. Muran PJ. Mercury elimination with oral DMPS, DMSA, vitamin C, and glutathione: an observational clinical review. Altern Ther Health Med 2006; 12:70-5.

18. Khan DA, Qayyum S, Saleem S, Khan FA. Lead-induced oxidative stress adversely affects health of the occupational workers. Toxicol Ind Health 2008; 24:611-8.

19. Staessen JA, Lauwerys RR, Buchet JP, et al. Impairment of renal function withincreasing blood lead concentrations in the general population. The Cadmibel Study Group. N Engl J Med 1992; 327:151-6.

20. Payton M, Hu H, Sparrow D, Weiss ST. Low-level lead exposure and renal function in the Normative Aging Study. Am J Epidemiol 1994; 140:821-9.

21. Kim R, Rotnitsky A, Sparrow D, et al. A longitudinal study of low-level lead exposure and impairment of renal function. The Normative Aging Study. JAMA 1996;275:1177-81.

22. Lin JL, Lim PS. Disappearance of immune deposits with EDTA chelation therapy in a case of IgA nephropathy. Am J Nephrol 1992; 12:457-60.

23. Lin JL, Yeh KH, Tseng HC, et al. Urinary $\mathrm{N}$-acetyl-glucosaminidase excretion and environmental lead exposure. Am J Nephrol 1993; 13:442-7. 